This item was submitted to Loughborough's Research Repository by the author.

Items in Figshare are protected by copyright, with all rights reserved, unless otherwise indicated.

\title{
Preliminary evaluation of variables for communicating uncertainties using a
} Haptic seat

PLEASE CITE THE PUBLISHED VERSION

https://doi.org/10.1145/3239092.3265959

PUBLISHER

ACM

VERSION

AM (Accepted Manuscript)

LICENCE

CC BY-NC-ND 4.0

\section{REPOSITORY RECORD}

Kunze, Alexander, Steve Summerskill, Russell Marshall, and Ashleigh J. Filtness. 2019. "Preliminary Evaluation of Variables for Communicating Uncertainties Using a Haptic Seat". figshare.

https://hdl.handle.net/2134/35094. 


\section{Preliminary Evaluation of Variables for Communicating Uncertainties Using a Haptic Seat}

\author{
Alexander Kunze \\ Loughborough Design School \\ Loughborough University \\ Loughborough, LE11 3TU, UK \\ A.Kunze@lboro.ac.uk

\section{Russell Marshall} \\ Loughborough Design School \\ Loughborough University \\ Loughborough, LE11 3TU, UK \\ R.Marshall@lboro.ac.uk
}

Stephen J. Summerskill

Loughborough Design School

Loughborough University

Ashleigh J. Filtness

Loughborough Design School Loughborough University

Loughborough, LE11 3TU, UK Loughborough, LE11 3TU, UK

S.J.Summerskill2@lboro.ac.uk A.J.Filtness@lboro.ac.uk
Permission to make digital or hard copies of all or part of this work for personal or classroom use is granted without fee provided that copies are not made or distributed for profit or commercial advantage and that copies bear this notice and the full citation on the first page. Copyrights for components of this work owned by others than ACM must be honored. Abstracting with credit is permitted. To copy otherwise, or republish, to post on servers or to redistribute to lists, requires prior specific permission and/or a fee. Request permissions from permissions@acm.org.

ACM

AutomotiveUl '18 Adjunct,, September 23-25, 2018, Toronto, ON, Canada ACM 978-1-4503-5947-4/18/09.

https://doi.org/10.1145/3239092 3265959

\begin{abstract}
Recent findings have indicated that the communication of uncertainties is a promising approach for overcoming human factors challenges associated with overtrust issues. The existing approaches, however, are limited in that they require operators to monitor the instrument cluster to perceive changes. As a consequence, significant changes may be missed and operators are regularly interrupted in the execution of non-driving related tasks even if the system is performing well. To overcome this, unobtrusive interfaces are required that are only interruptive if needed. This paper presents a lab-based study aiming at the preliminary evaluation of haptic variables for communicating automation uncertainties using a haptic vehicle seat. The initial results indicate that particularly increases in amplitude as well as a rhythm consisting of long vibrations separated by short breaks are well suited for communicating the exceedance of specified uncertainty thresholds. The communication of decreases in uncertainty using vibration cannot be recommended.
\end{abstract}

\section{Author Keywords}

Uncertainties; haptic; seat vibration

\section{CCS Concepts}

-Human-centered computing $\rightarrow$ User interface design; Haptic devices; $\mathrm{HCl}$ theory, concepts and models; 


\section{Introduction}

The iterative approach to achieving full driving automation entails significant human factors challenges [4]. In particular, expecting human operators to resume the driving task following automation failures may lead to critical situations, partially due to a lack of situation awareness and overtrust issues $[3,7]$. Researchers have suggested to communicate the uncertainties of the automated system in order to calibrate operator trust and prepare users for potentially imminent failures $[1,5]$. However, while the existing approaches have indicated benefits in terms of driving safety following takeovers, it seems unlikely that the proposed interface concepts will prove to be valuable in practice. Foremostly, both publications used visual displays to convey uncertainties. This requires users to regularly glance to the instrument cluster in order to perceive changes. Particularly when considering the usage context, which will likely involve visual non-driving related tasks (NDRTs) [8], this impedes the prolonged usage uncertainty displays. Instead, an (for the majority of time) unobtrusive interface is needed that attracts the attention of the user as uncertainties increase and a takeover becomes increasingly likely. One approach of achieving this is to communicate significant changes in uncertainty with haptic feedback. Several publications have explored the use of a haptic seat to communicate information, for instance navigational content [2] or takeovers [9]. Compared with the visual and auditory perceptual channels, the tactile channel is characterised by very fast perception dwell times [12] and is likely not preoccupied with NDRTs.

The study presented in this paper examines a set of fundamental haptic variables in terms of their suitability for communicating changes in uncertainty. Thereby not only the exceedance of thresholds is of interest but also instances in which uncertainties drop below the threshold. As such, this



Figure 1: Position of vibration motors in vehicle seat

study investigates how clearly different variables communicate increases and decreases in uncertainty.

\section{Preliminary Evaluation of Variables}

A comparative study was conducted to address the research question. Similar to prior publications $[10,6]$, the design variables amplitude, position, movement, and rhythm were chosen for examination.

Participants and Design

A total of 25 participants ( 7 female) with an average age of 32.64 years $(S D=10.00)$ participated in the experiment. The study was conducted with a within-subjects design whereby the sequence of variables was randomised to prevent order effects. 



Amplitude Positio

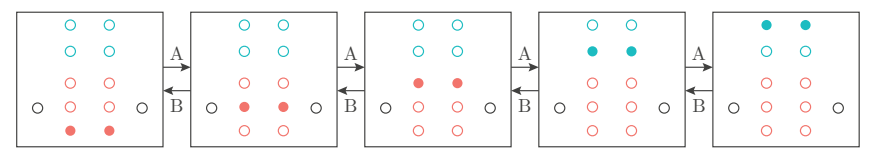

Movement



Figure 2: Haptic variables

\section{Apparatus and Procedure}

The study was conducted in a laboratory setting and participants were seated in a driving simulator consisting of three projectors and a vehicle cockpit for the duration of the study

\begin{tabular}{rc}
\hline Feature & Specification \\
\hline Op. voltage & $3 \mathrm{~V}$ \\
Op. current & $100 \mathrm{~mA}$ \\
N. amplitude & $7 \mathrm{G}$ \\
Body diameter & $8.7 \mathrm{~mm} \pm 0.2$ \\
\hline
\end{tabular}
(approximately 30 minutes). Throughout the experiment, the automated system was engaged and participants were not required to perform the driving task. The position (see Figure 1) and specification (see Table 1) of the eccentric vibration motors is consistent with prior publications [2]. The maximum vibration amplitude for seat pan and back rest was selected based on prior findings [6]. Participants were introduced to the study with a video explaining driving automation and the meaning of uncertainties. Following the introduction, the variables were evaluated in a randomised order. For each variable, two opposing patterns were de- voltage and current as well as diameter
Table 2: Descriptive statistics for the agreement with each statement regarding increasing/decreasing uncertainty

\begin{tabular}{lccccc}
\hline \multirow{2}{*}{ Variable } & & \multicolumn{4}{c}{ Direction } \\
\cline { 3 - 6 } & & \multicolumn{2}{c}{ Increasing } & \multicolumn{2}{c}{ Decreasing } \\
Amplitude & $\mathrm{A}$ & 5.68 & 1.14 & 2.20 & 1.15 \\
& $\mathrm{~B}$ & 4.88 & 1.90 & 3.04 & 1.86 \\
Movement & $\mathrm{A}$ & 5.08 & 1.71 & 2.64 & 1.63 \\
& $\mathrm{~B}$ & 4.64 & 1.93 & 3.24 & 2.03 \\
Position & $\mathrm{A}$ & 4.80 & 1.19 & 2.64 & 1.32 \\
& $\mathrm{~B}$ & 4.64 & 1.52 & 3.28 & 1.37 \\
Rhythm & $\mathrm{A}$ & 5.36 & 1.44 & 2.20 & 1.04 \\
& $\mathrm{~B}$ & 4.08 & 1.63 & 3.32 & 1.57 \\
\hline
\end{tabular}

signed (see Figure 2). The variable amplitude characterises an increase (pattern A) or decrease (pattern B) in vibration intensity. Movement was implemented through a successive activation of vibration motors up (pattern A) or down the seat (pattern B). Position was varied between back rest (pattern A) and seat pan (pattern B). Rhythm was varied between long vibrations with short breaks (pattern A) and short vibrations with long breaks (pattern B). Each pattern was presented three consecutive times to each participant, whereby the order of the patterns was randomised. For each pattern, participants had to indicate on a 7-point Likert scale to which degree they agree with the statement that the haptic pattern conveys that the uncertainty of the vehicle is (a) increasing and (b) decreasing. Prior to each pattern and question, the vibration was turned off.

\section{Results, Discussion and Limitations}

Table 2 and Figure 3 summarise the results of the study.

For all variable patterns, the agreement with the statement 


\section{Direction $\leftrightarrows$ Decreasing $\leftrightarrows$ Increasing}

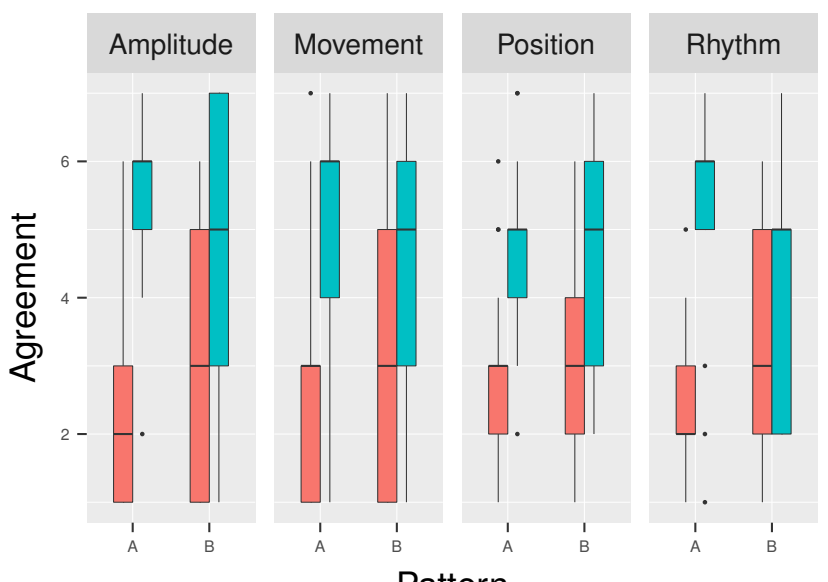

Pattern

Figure 3: Box plots for the responses regarding each variable pattern

that the uncertainty is increasing was higher than that for the opposing statement. Paired t-tests were conducted to examine the significance of the differences (see Table 3) [11]. Except for pattern B of movement and rhythm, all ttests returned significant results, indicating that it is more intuitive to associate haptic feedback with increases in uncertainty rather than decreases. Overall, pattern A of the variables amplitude $(M=5.68, S D=1.14)$ and rhythm ( $M=5.36, S D=1.04$ ) received the highest scores regarding the communication of an increase in uncertainty. Further, the differences between the opposing directions (increasing/decreasing uncertainty) were highest for these patterns. The results indicate that particularly a pattern that gradually increases the vibration intensity (pattern A, amplitude) as well as a rhythm consisting of a long vibration (3s),
Table 3: Results of paired t-tests between responses regarding direction (increasing/decreasing)

\begin{tabular}{lccc}
\hline Variable & Pattern & t-test & MD \\
\hline \multirow{2}{*}{ Amplitude } & $\mathrm{A}$ & $t(24)=8.05^{* * *}$ & 3.48 \\
& $\mathrm{~B}$ & $t(24)=2.56^{*}$ & 1.84 \\
Movement & $\mathrm{A}$ & $t(24)=3.80^{* * *}$ & 2.44 \\
& $\mathrm{~B}$ & $t(24)=1.86$ & 1.40 \\
Position & $\mathrm{A}$ & $t(24)=4.73^{* * *}$ & 2.16 \\
& $\mathrm{~B}$ & $t(24)=2.54^{*}$ & 1.36 \\
Rhythm & $\mathrm{A}$ & $t(24)=6.97^{* * *}$ & 3.16 \\
& $\mathrm{~B}$ & $t(24)=1.28$ & 0.76 \\
\hline Significance levels: & ${ }^{* * *} p<.001{ }^{* *} p<.01$ & ${ }^{*} p<.05$
\end{tabular}

followed by a short break $(0.5 \mathrm{~s})$ and another long vibration (pattern A, rhythm) clearly communicate an increase in uncertainty. The presented results show the first implications for communicating uncertainties using haptic feedback. However, the findings must be validated in a driving context in order to ensure that participants can quickly interpret the haptic stimuli and respond accordingly. To ensure internal validity, several parameters were not varied, for instance the maximum amplitude. Further, the impact of gender, age, or weight on vibration intensity must be considered when implementing vibration into vehicle seats [6].

\section{Conclusion}

The initial results indicate that particularly increases in amplitude as well as a rhythm consisting of long vibrations $(3 \mathrm{~s})$ separated by short breaks $(0.5 s)$ are well suited for communicating the exceedance of specified uncertainty thresholds. Further, the communication of decreases in uncertainty using vibration cannot be recommended. 


\section{REFERENCES}

1. Johannes Beller, Matthias Heesen, and Mark Vollrath. 2013. Improving the Driver Automation Interaction: An Approach Using Automation Uncertainty. Human Factors: The Journal of the Human Factors and Ergonomics Society 55, 6 (2013), 1130-1141. DOI : http://dx.doi.org/10.1177/0018720813482327

2. Wonsuk Chang, Wonil Hwang, and Yong Gu Ji. 2011. Haptic seat interfaces for driver information and warning systems. International Journal of Human-Computer Interaction 27, 12 (2011), 1119-1132. DOI :

http://dx.doi.org/10.1080/10447318.2011.555321

3. Mica R. Endsley. 1995. Toward a Theory of Situation Awareness in Dynamic Systems. Human Factors: The Journal of the Human Factors and Ergonomics Society 37, 1 (1995), 32-64. DOI : http://dx.doi.org/10.1518/001872095779049543

4. Mica R. Endsley. 2017. From Here to Autonomy: Lessons Learned From Human-Automation Research. Human Factors The Journal of the Human Factors and Ergonomics Society 59, 1 (2017), 5-27. DOI : http://dx.doi.org/10.1177/0018720816681350

5. Tove Helldin. 2014. Transparency for Future Semi-Automated Systems. Ph.D. Dissertation. $\{\backslash$ "O\}rebro University.

http://www.his.se/pagefiles/11241/tove

6. Yong Gu Ji, Kwangil Lee, and Wonil Hwang. 2011. Haptic Perceptions in the Vehicle Seat. Human Factors and Ergonomics in Manufacturing \& Service Industries 21, 3 (2011), 305-325. DOI :

http://dx.doi.org/10.1002/hfm

7. Alexander Kunze, Russell Marshall, Stephen J. Summerskill, and Ashleigh J. Filtness. 2017.
Enhancing driving safety and user experience through unobtrusive and function-specific feedback. In Adjunct Proceedings of the 9th International ACM Conference on Automotive User Interfaces and Interactive Vehicular Applications (AutomotiveUI '17). ACM, Oldenburg, Germany, 183-189. DOI :

http://dx.doi.org/10.1145/3131726.3131762

8. T. M. Pickrell, R. Li, and S. KC. 2016. Driver Electronic Device Use in 2015 (Traffic Safety Facts Research Note. Report No. DOT HS 812 326). September 2016 (2016), 1-9. https://www.nhtsa.gov/sites/nhtsa. dot.gov/files/documents/driver

9. Matti Schwalk, Niko Kalogerakis, and Thomas Maier. 2015. Driver Support by a Vibrotactile Seat Matrix Recognition, Adequacy and Workload of Tactile Patterns in Take-over Scenarios During Automated Driving. Procedia Manufacturing 3 (2015), 2466-2473. DOI :

http://dx.doi.org/10.1016/j.promfg. 2015.07.507

10. B P Self, Jan B F Van Erp, L Eriksson, and Linda R. Elliott. 2008. Human factors issues of tactile displays for military environments. Tactile Displays for Orientation, Navigation and Communication in Air, Sea and Land Environments January (2008), 1-18.

11. Gail M. Sullivan and Anthony R. Artino. 2013. Analyzing and Interpreting Data From Likert-Type Scales. Journal of Graduate Medical Education 5, 4 (2013), 541-542. DOI : http://dx.doi.org/10.4300/JGME-5-4-18

12. Hermann Winner and Stephan Hakuli. 2012. Handbuch Fahrerassistenzsysteme (2nd ed.). Vieweg+Teubner Verlag, Wiesbaden. DOI :

http://dx.doi.org/10.1007/978-3-8348-8619-4 